\title{
Glue Ear in Children with Cleft Lip and Palate: An Update
}

\author{
Chin-Lung Kuo, MD, PhD*
}

1 Department of Otolaryngology, Taoyuan Armed Forces General Hospital, Taoyuan, Taiwan

2 Institute of Brain Science, National Yang-Ming University school of Medicine, Taipei, Taiwan

3 Department of Otolaryngology, Tri-Service General Hospital, National Defense Medical Center, Taipei, Taiwan

\begin{abstract}
Cleft lip/palate (CLP) in children is psychologically stressful for family members and debilitating for the patients themselves. These children must undergo a series of major invasive surgeries, including cleft lip repair surgery, cleft palate repair surgery, bone grafting surgery, and/or dental implant surgery. Unfortunately, the clinical significance of otitis media with effusion (OME), a complication associated with CLP, is often overlooked and very few studies have explored this condition in depth. In this paper, the author reviews the pathogenesis, clinical manifestations, and diagnoses of OME in children with CLP as well as the controversies surrounding treatment. We also provide a flowchart to guide the management of OME in children with CLP.
\end{abstract}

\section{Introduction}

Cleft lip/palate (CLP) is a congenital orofacial anomaly that is debilitating for patients and psychologically stressful for family members. Children with CLP are forced to undergo a series of major invasive surgeries, including surgery for cleft lip repair, bone grafting, and dental implants $[1,2]$.

Otitis media with effusion (OME), also called serous/secretory otitis media or glue ear, is a collection of non-purulent fluid within the middle ear space. OME is a common condition among infants and children between the ages of 1 and 3 years [3]. Compared to healthy children, children with CLP are more susceptible to OME $[4,5]$. Even though the vast majority of patients (approximately $80 \%$ ) do not have OME at birth [6], statistics have shown that OME occurs at least once before the first birthday in up to $90 \%$ of the infants born with CLP $[3,7]$. Furthermore, as many as $97 \%$ of the infants born with CLP suffer concurrent OME within the first two years of life [8].

The clinical significance of OME is often overlooked and very few studies have explored this condition in depth, despite the fact that it is commonly associated with CLP. The author summarizes and updates his previous work with the article partly borrowing from the author's earlier publications [4,9-21]. This paper presents a review of the pathogenesis, clinical manifestations, and diagnoses of OME in children with CLP as well as the controversies surrounding treatment. The author also provides a flowchart to guide the management of OME in children with CLP.

\section{Pathogenesis}

Numerous factors have been cited in the development of OME in children suffering from CLP, including (1) immature development of the Eustachian tube, (2) abnormalities in the muscle associated with the Eustachian tube, and (3) craniofacial bone abnormalities [4].

\section{Immature Development of the Eustachian Tube}

The Eustachian tube of children is not fully developed and therefore shorter than that of adults. It is positioned at a more horizontal angle, and the opening to the nasopharynx is narrower. Swelling and inflammation of the respiratory mucosa due to infection in the upper respiratory tract leave the narrow opening of the Eustachian tube susceptible to clogging, which can result in negative pressure in the middle ear. The position and length of the Eustachian tube allows viruses and bacteria from the upper respiratory tract to easily pass into the middle ear cavity, often leading to middle ear infection with effusion. Even in cases where the infection is well controlled, discharging fluid from the middle ear through the Eustachian tube to the throat is hindered by the short length, the horizontal position, and the narrow opening of the Eustachian tube. Fluid remaining in the middle ear can lead to OME [22-25].

\section{Abnormalities in the Muscles of the Eustachian Tube}

Anatomical or structural defects associated with cleft palate can affect velopharyngeal function. In children with CLP, the abnormal reflux of food and fluid from the mouth into the nasal cavity due to velopharyngeal insufficiency can result in inflammation and edema of the Eustachian orifices and hypertrophy of adenoid pads. This, in turn, can lead to tubal obstruction and secondary OME [22]. Abnormal development of the tensor veli palatini muscle (TVP) and levator veli palatini muscle in children with CLP can cause maladjustment in the regular opening of the Eustachian tube [26-28]. Changes in the atmospheric pressure (e.g., during descent in an airplane) or the absorption of gas in the middle ear by mucosa can prevent the Eustachian tube from opening to relieve pressure in the middle ear. The resulting negative pressure can cause the eardrum to retract, leading to the collection of fluid in the middle ear, which can again lead to OME [22].

\section{Craniofacial Bone Abnormalities}

The pathogenesis of OME in children with CLP has also been linked to other abnormalities in the structure of the Eustachian tube. These abnormalities include an increased nasopharyngeal space, alterations to the medial pterygoid plate and hamulus, a shorter tube, a larger angle between cartilage and TVP, a higher cartilage cell density, a smaller ratio of lateral and medial laminae area in cartilage, less curvature in the lumen, less elastin in the hinge portion of cartilage, and a lower insertion ratio of TVP to cartilage $[29,30]$. Kemaloglu et al. compared clinical and cephalometric data from 37 Japanese children with unilateral complete CLP or isolated cleft palate with those of 40 non-cleft children. They found that differences in the mastoid-middle ear-Eustachian tube system are associated with a tendency toward OME in CLP children. This fact helps to elucidate the pathogenesis of OME in children with CLP [31]. 


\section{Clinical Manifestations}

OME is often overlooked because it does not cause any symptoms of discomfort other than mild conductive hearing loss. In infants, OME and the associated hearing loss may continue without being detected for weeks or even months. Children with OME are also prone to poor sleep quality [32]. Parents of children with CLP should pay particular attention their child's reaction to sound as well as their interactions with other children. Any abnormalities warrant expert evaluation. More importantly, children should visit an otolaryngologist for a regular otologic examination to ascertain whether they are suffering from OME. Early diagnosis and treatment are invaluable in preventing or alleviating future hearing loss.

\section{Consequences of OME in CLP}

Children with CLP may suffer recurrent or continuous OME, which can lead to atelectasis, ossicular fixation, and/or tympanosclerosis [3,33,34]. The risk of chronic ear infection may be higher even in children with isolated cleft lip cases compared with unaffected controls [35]. The ear problems can result in conductive hearing loss of up to 30 decibels (dB). Researchers have previously shown that, regardless of whether they have undergone cleft palate repair surgery, as many as $90 \%$ of children with CLP suffer from OME or conductive hearing loss, while $50 \%$ suffer from recurrent otitis media [3,8,36-38]. In comparison, the prevalence of conductive hearing loss among children without CLP is $12.9 \%$. It is estimated that $50 \%$ of the individuals with this condition suffer from permanent conductive hearing loss by the time they reach adulthood $[39,40]$. Additionally, $0.9-5.9 \%$ of patients with CLP develop primary acquired cholesteatoma, the probability of which is $100-200$ times higher than among those without CLP $[41,42]$

Sensorineural losses have been ascribed to pathologic changes in the inner ear resulting from inflammation in the middle ear [4]. Toxins produced by long-term inflammation can pass through the round window or the oval window into the inner ear, often leading to permanent sensorineural hearing loss $[34,43]$.

Many studies have reported that reconstructive surgery for CLP can improve linguistic ability; however, language development depends on the extent to which hearing ability is maintained $[41,44]$. Long-term hearing loss due to improper treatment for OME can negatively influence language development of children [45]. Hearing loss in children suffering from CLP can also affect their academic comprehension and learning performance $[38,45-47]$. Bess et al. reported that academic performance can be seriously affected in up to $33 \%$ of children including those suffering hearing loss in only one ear. They also reported that up to $40 \%$ of patients are unable to participate in regular activities or interactions due to hearing loss [48]. It has been found that children with cleft palate are prone to specific psychological problems $[49,50]$. Children suffering from this condition may also display behavioral difficulties due to feelings of isolation [48].

\section{Examination and Diagnosis}

Up to $90 \%$ of infants born with CLP suffer from OME before their first birthday [3]; therefore, it is recommended that otologic tests be conducted as soon as possible after birth to ascertain whether fluid has collected in the middle ear $[39,51]$. The use of a pneumatic otoscope is the fastest and most direct method by which to inspect the eardrum for color and contour, and determining whether fluid has collected in the middle ear. It should be noted that the effectiveness of a pneumatic otoscope to test for OME depends on the experience and skill of the clinician, the patient's full cooperation, and the anatomical structure of the ear canal [3].

Videotelescopy is another method for inspecting the eardrum. A telescope is placed against the eardrum through the external ear canal, and a charge-coupled device (CCD) camera captures images of the eardrum. The resulting magnified images can be presented on a monitor, thereby allowing clinicians to accurately diagnose middle ear effusion [52]. Shiao et al. conducted a prospective study on the diagnostic efficacy of videotelescopy, pneumatic otoscopy, and tympanometry for the detection of pediatric OME. Their videotelescopy results achieved sensitivity of $97.8 \%$, specificity of $100 \%$, and accuracy of $98.0 \%$, significantly exceeding the ac- curacy of conventional tests using pneumatic otoscope and tympanometry [52]. Videotelescopy also provides visual information with which to validate the accuracy of results obtained using a pneumatic otoscopy.

The difficulties involved in administering pneumatic otoscopy or videotelescopy on newborns and small infants with CLP underline the importance of objective acoustic immittance testing plays [53]. Tympanometry is a common method of measuring pressure changes in the middle ear and the compliance of the eardrum [45,54]. Chen et al. found that the specificity of tympanometry was relatively low (only 59.6\%) when used to test for OME in infants with CLP. When used to test infants within nine months of age, specificity dropped to only 37.5\% [46]. Difficulties in maintaining airtight conditions in the ear when infants are crying or refusing to cooperate may also prevent the successful completion of the examination.

Pure tone audiometry can be used to facilitate the diagnosis of OME by revealing conductive or mixed hearing loss. Nonetheless, this method requires the cooperation of the patient and may therefore be unsuitable for children under three years of age [55]. Spectral gradient acoustic reflectometry (SGAR) may be an effective alternative to pure tone audiometry for patients in this age group. SGAR involves transmitting ultrasound waves to the eardrum and using a microcomputer to filter, record, and analyze the waves that are reflected back. SGAR is an efficient diagnostic tool for the detection of OME, requiring less than one second to complete the procedure. Although the sensitivity and specificity are somewhat low, SGAR is a noninvasive test that is unaffected by crying, cerumen, client cooperation, or the quality of the air seal with the ear, thereby making it useful for testing difficult infants [46,56-58].

\section{Watchful Waiting for OME}

Alt first identified the relationship between CLP and hearing impairment in 1878, and OME has been the subject of investigation ever since [59]. The severe complications caused by OME in CLP children can have far reaching consequences; therefore, determining the optimal treatment strategy is a topic worthy of in-depth exploration.

Many researchers have recommended watchful waiting as the treatment of choice for OME among children with CLP, particularly when parents prefer to avoid or postpone surgery. Muntz reported that more than $50 \%$ of CLP children who develop OME after 3 years of age naturally recover from $O M E$, and have no need to undergo ventilation tube surgery [60]. Flynn et al. studied the longitudinal prevalence of OME in CLP children between 7 and 16 years of age, and found that middle ear problems gradually dissipate between 7 and 13 years of age [61]. Rynnel-Dagöö et al. reported that $82 \%$ of CLP children with or without OME have normal hearing at 3-4 years of age, which is indicative of full recovery from OME [62]. Smith et al. reported that Eustachian tube function in most children with CLP improves significantly by the age of 6 to 7.5 years [63].

A number of researchers have reported that OME and Eustachian tube function improve as the patient grows older $[61,63,64]$, and therefore recommend watchful waiting for a period of three to six months from the diagnosis of effusion [61,63-65]. During the period of observation, the use of hearing aids can help patients to attain the hearing performance of children with ventilation tubes [65]; however, it should be noted that children may find hearing aids inconvenient or worry about the social stigma associated with wearing such devices $[45,66]$.

\section{Ventilation Tube Insertion (VTI) for OME}

Previous studies have shown that at least $90 \%$ of children who undergo palatoplasty for CLP continue to suffer recurrent OME [38], indicative of poor Eustachian tube function after repair surgery [67]. For this reason, many doctors prefer to perform cleft palate repair and ventilation tube surgery simultaneously when the child is one year old [3,34,68-70]. This combined surgical approach is done in the hope of overcoming the problem of middle ear effusion and improving the hearing ability of children, thereby enhancing their long-term linguistic development.

In the following, we present a summary of previous studies that addressed the effectiveness of ventilation tube insertion (VTI) for OME in CLP children. The studies summarized below measured outcomes 
using a variety of methods; however, we attempted to normalize their measurements. To deal with outcome measures on different scales, we summarized the findings as the percentage of ears presenting hearing loss or improvement. Grommet insertion frequency was summarized as the percentages of ears that underwent one or more grommet insertions and the number of times that insertion was performed. For complications or sequelae, the main summary measure was the occurrence of complications. Middle ear status was evaluated according to the rates of OME recurrence and resolution, and the percentage of ears presenting various types of tympanogram.

\section{Comparative Effectiveness: Hearing Outcomes}

\section{CLP children versus age-matched non-CLP children}

Two studies compared CLP children with age-matched healthy children with regard to hearing outcomes after VTI for OME [71,72]. One prospective study with an excellent study design reported similar hearing outcomes in children with and without palate conditions (CLP group 10.5 $\mathrm{dB}$ versus control group $10.9 \mathrm{~dB}, \mathrm{P}>0.05$, follow-up 5-7 years) over the short-term [71]. Another retrospective study reported a significantly higher percentage of ears with hearing loss in the CLP children versus the age-matched non-CLP children (CLP group 24\% versus control group $0 \%$, follow-up 3-5 years) [72]. However, $64 \%$ of children in the CLP group underwent VTI, while only $6 \%$ in the non-CLP group underwent VTI $(P<$ 0.0005).

\section{Pre-VTI versus post-VTI hearing outcomes}

Hearing outcomes were evaluated in several case-series studies [33,41,63,73-77]. Over the long-term, between $50 \%$ and $94 \%$ of CLP children recovered normal hearing after being administered VTI in conjunction with palatoplasty (follow-up 5.5-15.4 years) [33,63,74-77]. Children requiring a higher number of VTIs faced a significantly elevated risk of long-standing hearing loss $[33,41]$.

\section{VTI versus non-VTI}

Zheng et al. conducted a randomized controlled trial to determine the effectiveness of grommets on hearing recovery among CLP children with OME [78]. They reported hearing improvement in only 22 of 39 CLP children with VTI; however, no hearing results were obtained from those that did not undergo VTI. Furthermore, the authors reported hearing outcomes only over the short-term (6 months of observation). The lack of data pertaining to long-term outcomes makes it difficult to interpret these results.

Several prospective $[71,79,80]$ and retrospective $[38,64,66,72,81-88]$ cohort studies evaluated hearing outcomes. Among these cohort studies, several compared VTI with non-VTI (i.e., myringotomy alone, hearing aids, and watchful waiting) $[64,80,82,84-88]$. It has been reported that the improvements in hearing afforded by VTI over the short-term (within 18 months after $\mathrm{VTI}$ ) are more pronounced than those from myringotomy, watchful waiting, or hearing aids [84-86]. Potsic et al. found that, compared with CLP children without VTI for OME, those with VTI had a lower percentage of ears presenting hearing loss over the short-term (less than 5 years) [88]. As for long-term hearing outcomes, Hubbard et al. reported that the benefits of early VTI (3 month of age) exceeded those of more conservative approaches to treatment [80].

Despite the fact that most studies on hearing outcomes have advocated VTI for CLP children, a number of researchers have expressed reservations based on conflicting results. In a number of cohort studies, CLP children that underwent VTI for OME presented worse hearing outcomes over the short-term (less than 5 years) [64] or a higher percentage of ears with hearing loss after surgery over the long-term (9-21 years), compared to children that did not undergo the procedure $[82,87]$.

\section{Summary of evidence on hearing outcomes}

More than half (50\%-94\%) of CLP children recover normal hearing 5-15 years after VTI [33,63,74-77]. Compared with conservative management, most studies have shown that VTI is beneficial to hearing recovery over the short- as well as long-term $[80,84-86,88]$ There remains a belief that early VTI at the time of palatoplasty is beneficial; however [89], there is little evidence indicating the optimal timing for grommet insertion.

\section{Comparative Effectiveness for Speech and Language Outcomes} CLP children versus age- and sex-matched non-CLP control

One article compared CLP children with age- and sex-matched non-CLP controls with regard to post-VTI speech and language outcomes [89]. Normal or near normal speech intelligibility ratings were similar among CLP (90\%) and non-CLP children (96\%).

\section{VTI versus non-VTI}

Several researchers have assessed speech and language outcomes in CLP patients with OME using prospective [80] as well as retrospective cohort studies [64,89-92]. Five articles compared children that were or were not administered VTI for OME. [64,80,90-92]. No differences in speech or language development were observed in short-term (0-5 years) [64,92] or long-term (8-10 years) [90,91] follow-ups. With one exception, all investigators used the same number of CLP children matched for cleft type, age, sex, socioeconomic status, and birth order. After a 9-year follow-up, consonant articulation was found to be better among children who underwent early VTI $(P=0.03)$ [80]. However, the fact that myringotomy was performed on the control group (when deemed necessary) prevents the clear elucidation of differences in functional outcome between children that did or did not undergo VTI for OME.

\section{Summary of evidence on speech and language outcomes}

No differences in speech or language development were observed between CLP children who underwent conservative observation and those who underwent aggressive $\mathrm{VTI}$, over the short-term (0-5 years) $[64,92]$ or long-term (8-10 years) [90,91]. Further, assessments of speech by Merrick et al. revealed a similar percentage of children with normal or near normal speech-intelligibility ratings in the CLP and non-CLP groups [89]. These findings indicate that speech and language skills do not depend on the VTI approach to OME treatment but rather on the timing of palatoplasty.

\section{Complications of VTI}

\section{CLP children versus age-matched healthy children}

Two studies compared age-matched healthy control children with regard to VTI complications [71,72]. One study showed that the prognosis of children with CLP who underwent early VTI is comparable to that of children without CLP [71]; however, the other study reported contradictory results with higher rates of complications among CLP children [72].

\section{VTI versus non-VTI}

Several retrospective cohort studies compared children with and without VTI (i.e., hearing aids or watchful waiting) with regard to post-VTI complications $[64,66,81,82,86,87,92]$. Those studies reported higher complication rates among children with VTI than among those without, over the short-term ( $<5$ years of follow-up) $[64,66,81,86,92]$ as well as long-term $(9$ to 21 years of observation) $[82,87]$. All results were statistically significant; however, differences were not calculated in two of the studies $[82,92]$.

Among the various types of complication, tympanosclerosis and otorrhea generally presented transient but common sequelae following VTI $[93,94]$. Other studies reported permanent perforations and cholesteatoma $[93,95,96]$. The evidence was too limited and blurred with regard to the occlusion of grommets, infection, and the presence of granulation tissue to determine the direction of effects between VTI and adverse events in CLP children with OME.

\section{Tympanosclerosis}

Tympanosclerosis has little influence on hearing [33,92,97]; however, this is the most common VTI-related complication, the rates of which range from 0 to $52 \%[6,38,64,66,72-74,77,78,81,85,87,92,98]$. Tympanosclerosis can cause conductive hearing loss (albeit rarely) if it extensively involves the ossicular chain [92].

\section{Otorrhea}

Otorrhea is a complication of the tympanostomy tubes in children who 
are otherwise healthy [99]. This condition has not been systematically studied in CLP children after VTI. A number of studies have reported that the probability of post-VTI otorrhea in CLP children is low (4\% to $11.5 \%$ ) $[64,70,86,99]$, whereas other studies have reported inconsistent results (55\% to 68\%) $[50,77,98]$. Thus, evidence is inconclusive. Otorrhea appears to be more common in ears that underwent VTI than in ears that did not [86]. However, the evidence is insufficient to reveal an association between the long-term use of grommets and otorrhea. Only one study on post-VTI otorrhea reported on the management of otorrhea [92]. Freeland et al. found that although $68 \%$ of infants developed otorrhea following the use of grommets over a mean duration of 3.9 months, otorrhea usually responded promptly to antibiotic-corticosteroid drops or systemic antibiotic treatment in more resistant cases.

\section{Eardrum perforation}

Among CPL children, eardrum perforation occurred in $0 \%$ to $19 \%$ of VT-treated ears in follow-ups of $1-15$ years $[6,33,38,63,64,66,70-74,76$ $78,80,81,86,87,90,92,98,100]$. In a study by Shapiro, the rate of eardrum perforation reached $50 \%$ after VTI [101]; however, the number of children with VTI (only six children) was too small to be of value as a reference (low-quality study design). In contrast, eardrum perforation was observed in only $0 \%$ to $7 \%$ of non-VT-treated ears (i.e., patients underwent observation or were given hearing aids) during follow-ups of 1-4 years $[81,86,92]$. In non-CLP children with OME, only one study reported postVTI eardrum perforation within a 5-year follow-up (incidence of 3\%) [71].

\section{Cholesteatoma}

Grommet insertion is reportedly an iatrogenic cause of secondary acquired cholesteatoma $[12,13,15,17,102,103]$. The development of the disease is uncommon, with a reported rate of approximately $1 \%$ among non-CLP children with VTI $[93,104]$. However, evidence has shown that the CLP children are at elevated risk of developing cholesteatoma [86,93], with a rate of $0 \%$ to $6.9 \%$ within 12 years after VTI $[33,41,78,82,86,87,93$, $100,101,105]$.

It should be noted that Hornigold et al. reported an incidence of $29 \%$ among CLP children 21 years after VTI for OME [82]. Similarly, Spilsbury et al. conducted a retrospective cohort study on the relationship between CLP and secondary cholesteatoma following VTI in children [93]. They examined the complete hospital in-patient history of a large unselected population (869 CLP children versus 56,080 non-CLP children) over a 29-year period. The authors reported that children with CLP developed cholesteatoma 7.5 times faster after the first VTI, compared to children without CLP (95\% confidence interval, 3.8-18.2).

\section{Summary of evidence on VTI complications}

CLP children with VTI generally have a higher risk of complications than do those without, over the short-term (less than 5 years) $[64,66,81,86,92]$ as well as long-term (9 to 21 years) $[82,87]$. However, there is insufficient evidence to draw any conclusions due to conflicting results among these studies on CLP and non-CLP children [71,72].

\section{Comparative Effectiveness for Middle Ear Status}

Previous studies have compared the effect of VTI on middle ear using outcome measurements including the rates of OME resolution, persistent OME, and OME recurrence. The rates of OME resolution were reported in three high-quality studies: a randomized control trial, a prospective cohort study, and a retrospective cohort study $[70,71,78]$. The rates of OME resolution ranged from $48.7 \%$ to $86 \%$ within the first 6.5 years. These results were supported by Goudy et al., who reported a median resolution time of conductive hearing loss of approximately 5 years [41]. Kuşcu et al. observed that normal otoscopic examination findings were higher in CLP children without VTI than in those with VTI [106].

Persistent OME was observed in $29 \%$ to $52 \%$ of CLP children within 4-7 years after VTI $[38,64,88,92]$. Gordon et al. [87] found that only $5 \%$ of CLP children had persistent OME 9 years or more after palatoplasty with VTI, concluding that Eustachian tube function may be adequate by the age of 9 years. These results are supported by Smith, et al. [63], who found that Eustachian tube function eventually returned to normal in most CLP children, and that the age of Eustachian tube normalization was approximately 8 years (range $1.5-17.3$ years). A number of studies have reported that $17 \%$ to $45 \%$ of CLP children experienced OME recurrence 3-6 years after VTI, at a mean age of approximately 7 years $[38,76,77,81]$.

\section{CLP children versus non-CLP control}

Four articles reported on post-VTI middle ear function in CLP and nonCLP children [71,72,79,89], three of which included an age-matched non-CLP control group $[71,72,89]$. The results in studies by Ovesen \& Blegvad-Andersen [72] and Broen et al. [79] were not considered for further interpretation because only $6 \%$ and $31 \%$ of the non-CLP children with OME underwent VTI, respectively. Merrick, et al. reported comparable rates of persistent OME in children with and without cleft palate (24\% versus $14 \%, P=0.31$ ) [89]. Valtonen et al. reported similar OME resolution rates in CLP and non-CLP children (64.1\% versus 60.6\%) [71]. In summary, the prognosis for middle ear recovery among CLP children with early VTI is comparable to that of children without CLP.

\section{VTI versus non-VTI}

Zheng et al. performed a randomized controlled trial comparing OME resolution rates between CLP children with and without VTI [78]. They reported a significantly higher OME resolution rate (48.7\%) among children who underwent palatoplasty and VTI than among those who underwent palatoplasty alone $(24.5 \%, \mathrm{P}<0.01)$. Children with VTI were observed for shorter periods ( 6 months versus 20 months); however, the authors expected that the OME resolution rate would have been higher if the children had been followed up for the same period as those without VTI; i.e., the difference in resolution rates between the groups would have become increasingly pronounced over time. Potsic et al. [88] reported that CLP children that did not undergo VTI had a significantly higher rate of persistent OME at the age of 5 than did those with VTI. Freeland et al. [92] obtained the same results for CLP children at the age of 4 years. However, two other studies reported conflicting results; i.e., a higher rate of persistent OME among CLP children with VTI [64,87].

\section{Summary of evidence on middle ear status}

Three high-quality studies reported that more than half (48.7\% to $86 \%$ ) of the CLP children who underwent VTI presented OME resolution within the first 6.5 years $[70,71,78]$. The median resolution time of conductive hearing loss was approximately 5 years [41]. These high OME resolution rates were supported by four other studies, in which persistent OME was observed in less than half of the CLP children (29\% to $52 \%$ ) in the first 4-7 years after VTI $[38,64,88,92]$. Eustachian tube function began to normalize by $7-9$ years of age $[38,63,64,70,71,78,87,88,92]$. In addition, fewer than half of the CLP children ( $17 \%$ to $45 \%)$ presented OME recurrence within the first 3-6 years of follow-up $[38,76,77,81]$. Importantly, the prognosis for CLP children that underwent early VTI was comparable to that of the children without CLP.

\section{Frequency of Grommet Insertion}

A significant proportion (53.2\% to $98 \%$ ) of CLP children with OME require VTI $[6,71,74,81,98]$, with an average of between 0.55 to 2.2 VTIs per patient in the first 7 years of observation $[38,64,79,86]$. Cleft defects play an important role in OME formation; therefore, it would be reasonable to assume that children with more overt palatal malformations have a greater need for grommets. This assumption has been supported by several studies $[87,91,105]$, in which a relationship was established between the degree of the cleft and the frequency of VTI, with severe or complete clefts more likely to involve grommet insertion. Children with cleft palate had a significantly higher frequency of VTIs than did those without $[71,79]$. However, this issue requires further investigation. Lithovius et al. reported that the severity of the cleft was not a significant factor in determining the number of required ventilation tubes [107]. The choice of surgical technique for the repair of cleft palate is not significantly associated with the number of VTIs required [107]; however, palatoplasty may indeed decrease the likelihood of ventilation tube re-insertion in children with cleft palate, as evidenced by a recent population-based study [108].

Summary of evidence pertaining to effectiveness of VTI for OME 
Compared with a conservative approach, early VTI has been shown to improve hearing, and this improvement was maintained in more than half of the CLP children for a period of 5-15 years after surgery. Nonetheless, VTI does not necessarily lead to improvements in speech or language development in CLP children, and CLP children with VTI were shown to face a higher risk of complications than did those without. It appears that VTI is beneficial in helping CLP patients to recover from OME. Nonetheless, there is insufficient evidence to suggest the optimal timing of VTI (e.g., at the time of repair of lip/palate), although it may be convenient for surgeons to combine these procedures.

\section{Limitations of Previous Studies}

Despite considerable research into the subgroups of CLP children with regard to the effectiveness of grommets for OME, heterogeneity in the design of studies has proven a formidable barrier to the synthesis of evidence $[10,14]$. Most previous studies failed to clearly describe their criteria in the definition of OME. Previous studies included patients covering a range of ages with different types of cleft who had undergone different procedures and employed different criteria for VTI. Grommet insertion (unilateral or bilateral) was treated as a single procedure in some studies and as two procedures in other studies. The measures used in the studies were non-uniform; i.e., different time points were used for the determination of outcomes and baseline measures were not always provided. Studies also varied in the length of observation periods. Most studies in this review were retrospective studies. Only otologic findings during a particular month, or interpolation from examinations in adjoining months, were used to derive the monthly status of each ear. Thus, patient history was of limited value because it was difficult to determine when grommets were extruded and whether ear drainage occurred. These mixed results made it impossible to calculate statistical differences for each complication; hence, it is still unclear whether the differences reached statistical significance. Finally, the issue of missing data was not taken into account.

\section{Debate Concerning Selection of Treatment Strategy}

A review of previous studies has shown that there is currently no consensus as to the optimal method for the treatment of OME, and many researchers are at odds over this subject [66]. Most previous studies have been based on retrospective analysis; however, they can vary widely in design. This makes it difficult to assemble informative meaningful comparison. Even in prospective studies on OME in CLP children [71,78,79], there remains a lack of high-quality, adequately-powered randomized controlled trials. One reason may be that most parents require recommendations pertaining to treatment, rather than allowing their child to be randomly included in an experimental or control group, particularly children who have undergone or will undergo a series of major invasive surgeries. Thus, it is currently impossible to conduct a meta-analysis of previous research summarizing treatment methods and/or provide guidance with regard to treatment choices $[3,65]$.

\section{Clinical Guidelines}

\section{NICE Clinical Guideline}

The UK National Institute for Health and Clinical Excellence (NICE) has published clinical guidelines for the surgical treatment of OME in children with or without CLP [65]. Those guidelines indicate that there is currently insufficient evidence to prove that simultaneous cleft palate repair surgery and ventilation tube surgery is an effective approach to the alleviation of OME. Thus, the simultaneous insertion of a ventilation tube during the surgical repair of a cleft palate is not recommended unless careful otological and audiological assessments have been performed. The guidelines recommend that treatment be based on the needs and desires of children and their parents, and that ventilation tube surgery be viewed as an alternative to hearing aids in CLP children with persistent bilateral OME and hearing loss [65,109].

\section{Clinical Guidelines of AAO-HNSF, AAP, and AAFP}

Updated clinical guidelines have recently been published for OME. These guidelines were co-developed by the American Academy of Otolaryngology-Head and Neck Surgery Foundation (AAO-HNSF), the American Acad- emy of Pediatrics (AAP), and the American Academy of Family Physicians (AAFP) [110]. The group in charge of updating the guidelines has claimed that it may be appropriate to offer tympanostomy tubes on an individual basis for cleft palate infants with OME that persists after failing hearing tests. They claim that resolving the issue of middle ear effusion could facilitate the assessment of hearing status.

It has also been recommended that clinicians evaluate children with cleft palate for OME and hearing loss at the time when cleft palate is first diagnosed. Monitoring for OME and hearing loss should continue throughout childhood, including after palate repair. The guideline update group recommends that middle ear status be assessed at 12 to 18 months of age, considering that this is a critical period in the development of language skills, speech, balance, and coordination. By 18 months of age, delays in language and speech development are easily identified.

In these guidelines, it is recommended that VTI be considered when type B tympanogram or OME persists for 3 months or longer. These recommendations are based on the assumption that the likelihood of spontaneous resolution is low. For children who do not receive tympanostomy tubes, the follow-up schedule to monitor OME and hearing loss until OME resolves should be more frequent than the 3- to 6-month intervals recommended for children without cleft palate.

\section{PRISMA-compliant Systematic Review}

Many clinical guides fail to provide clear recommendations with regard to treatment approaches, due to a lack of conclusive studies $[45,111]$. Despite the fact that a number of reviews have been published on treatment choices for the management of OME in CLP children, a number of these are narrative reviews [4,22,112-114], whereas others are systematic reviews pertaining mainly to otherwise healthy children $[45,65,97,111,115$ 121]. The lack of research on the CLP subgroup of children means that there is currently no evidence-based information for clinicians or parents indicating the effectiveness of grommets for OME in CLP children.

Ponduri et al. performed a systematic review on the routine early insertion of grommets for OME in CLP children [3]. The authors concluded that there is currently insufficient evidence on which to base recommendations pertaining to clinical practice in this area. However, they did not perform data synthesis dealing with patient-centered outcomes, nor did they provide a detailed, well-described protocol, such as the Cochrane system [122] or the Preferred Reporting Items for Systematic Reviews and Meta-analyses (PRISMA) [123]. A systematic review based on pre-defined eligibility criteria, conducted in accordance with a pre-defined methodological approach, could facilitate the appraisal of review methods and elucidate modifications to methods and selective reporting in completed reviews [124].

A systematic review by Kuo et al. published in PEDIATRICS addressed the effects of VTI in children with cleft palate and OME from the perspective of patient-centered outcomes [11]. The review followed the protocol outlined in PRISMA to allow full and transparent assessment of the existing literature, in order to provide evidence-based information pertaining to the management of OME in children with cleft palate.

That review revealed that $38 \%$ to $53 \%$ of CLP children underwent VTI for $\mathrm{OME}$, and that more severe cases were more likely to undergo grommet insertion. Compared with a conservative approach, it appears that VTI may improve hearing outcomes in CLP children, and that these improvements could last for at least 1-9 years after surgery. In addition, children who have undergone VTI face a higher risk of complications than do those who have not received this form of treatment. The most common post-VTI complications include eardrum retraction and tympanosclerosis, with incidence rates of $11 \%$ to $37 \%$. Of particular importance is the need to perform grommet insertion within a highly specified time frame. The authors concluded that existing evidence is insufficient to support any assertions with regard to the use of grommets, either therapeutically or prophylactically, at the time of palatoplasty or afterward.

\section{Future Research Requirements}

In the future, there may be a need to develop rigorous methodologies for the examination of functional outcomes in CLP children after VTI. Further multi-institute prospective studies or well-designed randomized con- 


\section{REVIEW}

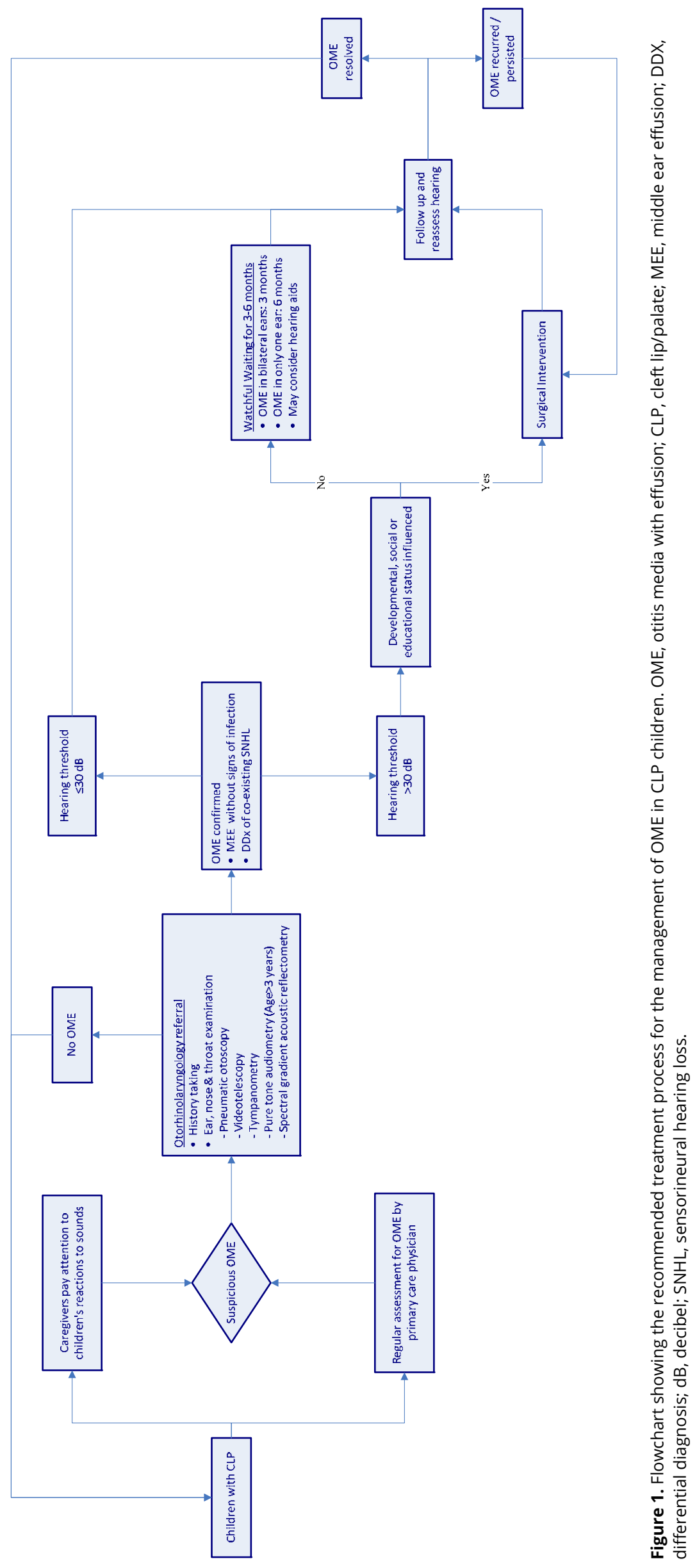


trolled trials are needed to develop a comprehensive base of evidence sufficient to clarify the effectiveness of VTI for OME in CLP children.

\section{Recommendations for Management}

Strategies related to the treatment of OME in CLP children are still under debate, and there is insufficient evidence with which to establish absolute guidelines. We believe that the lack of consensus regarding the optimal treatment for OME in CLP children should prompt caregivers to adopt a relatively conservative approach. Patients and parents should also be given a range of treatment options based on their individual needs and desires.

Figure 1 presents a flowchart showing the recommended process for OME management in CLP children. From the time of birth, children with CLP should undergo continual and regular otologic examinations and audiological monitoring for the assessment of OME. Children with delayed speech and/or language development should be suspected of having OME and referred to an otolaryngologist. Once OME is confirmed, the co-existing sensorineural component of hearing loss should be further investigated. It is recommended that children suffering from middle ear effusion without significant hearing loss (hearing threshold $\leq 30 \mathrm{~dB}$ ) remain under observation [65]. Children with hearing loss exceeding 30 $\mathrm{dB}$ can be managed through active observation for 3 months or alternatively referred for surgery, in accordance with the child's developmental, social, and educational status. If a patient suffers OME in only one ear, the observation period may be extended to 6 months [69]. During the observation period, hearing aids could be considered [125]. Patients suffering from recurrent OME following surgery may undergo repeated ventilation tube surgery, and those in whom the disease persists after an observation period of 3 to 6 months may be referred for surgery.

\section{Summary and Conclusion}

Otitis media with effusion associated with Eustachian tube dysfunction can seriously affect hearing in children with CLP, which can lead to linguistic and speech disorders, and ultimately to the disruption of learning and development. Compared with watchful waiting or hearing aids, VTI has been shown to improve hearing in more than half of CLP children 5-15 years after surgery. VTI and more conservative approaches do not appear to differ with regard to speech and language outcomes. CLP children who undergo VTI present a higher risk of complications than do children without VTI. It has been shown that VTI is beneficial in helping CLP patients to recover from OME. There is insufficient evidence to indicate the preferred timing of VTI (e.g., prophylactic insertion during repair of lip or palate). This summary is based on under-powered studies, and the evidence for each outcome is inconclusive. The lack of concrete evidence pertaining to the optimal treatment for OME in CLP children should prompt caregivers to adopt a relatively conservative approach. Most importantly, the needs of children and their parents must be taken into consideration. Only a consensus between patients/parents and surgeons regarding the most suitable treatment strategy for OME can ensure the greatest benefits.

\section{Article Information}

*Correspondence: Chin-Lung Kuo, MD, PhD

Department of Otolaryngology, Taoyuan Armed Forces General Hospital, Taoyuan, Taiwan. E-mail: drkuochinlung@gmail.com

Received: Mar. 31, 2018; Accepted: Apr. 27, 2018; Published: May 18, 2018

DOI: 10.24983/scitemed.cmt.2018.00062

Copyright (c) 2018 The Author. This is an open-access article distributed under the terms of the Creative Commons Attribution 4.0 International License (CC-BY).

Funding: This study was sponsored by grants from Medical Affairs Bureau Ministry of National Defense (MAB-107-099) and Taoyuan Armed
Forces General Hospital (AFTYGH No. 10734).

\section{Conflict of Interest: None}

\section{Acknowledgment}

The article partly borrows from the author's earlier publications.

\section{Keywords}

Conductive hearing loss; grommet tube; middle ear effusion; otitis media; review.

\section{References}

1. Lilja J. Cleft lip and palate surgery. Scand J Surg 2003;92(4):269-273.

2. Lou $\mathrm{Q}$, Zhu H, Luo $\mathrm{Y}$, et al. The effects of age at cleft palate repair on middle ear function and hearing level. Cleft Palate Craniofac J 2018;55(5):753-757.

3. Ponduri S, Bradley R, Ellis PE, Brookes ST, Sandy JR, Ness AR. The management of otitis media with early routine insertion of grommets in children with cleft palate - A systematic review. Cleft Palate Craniofac J 2009; 46(1):30-38.

4. Kuo CL, Lien CF, Chu CH, Shiao AS. Otitis media with effusion in children with cleft lip and palate: a narrative review. Int J Pediatr Otorhinolaryngol 2013;77(9):1403-1409.

5. Ungkanont K, Boonyabut $\mathrm{P}$, Komoltri C, Tanphaichitr A, Vathanophas V. Surveillance of otitis media with effusion in Thai children with cleft palate: cumulative incidence and outcome of the management. Cleft Palate Craniofac J 2018;55(4):590-595.

6. Szabo C, Langevin K, Schoem S, Mabry K. Treatment of persistent middle ear effusion in cleft palate patients. Int J Pediatr Otorhinolaryngol 2010;74(8):874-877.

7. Lewis CW, Jacob LS, Lehmann CU, Section On Oral Health. The primary care pediatrician and the care of children with cleft lip and/or cleft palate. Pediatrics 2017;139(5):e20170628.

8. Dhillon RS. The middle ear in cleft palate children pre and post palatal closure. J R Soc Med 1988;81(12):710-713.

9. Kuo $\mathrm{CL}$, Shiao AS. Chapter 6: Tympanostomy tube placement for otitis media with effusion in children with cleft lip and palate; designing strategies for cleft lip and palate care. Mazen Ahmad Almasri, IntechOpen.

10. Kuo $\mathrm{CL}$, Tsao $\mathrm{YH}$, Shiao AS. Critical reassessment of the probability of receiving additional ventilation tube insertion for recurrent otitis media with effusion in children with cleft palate. Acta Otolaryngol 2015;135(5):519-520.

11. Kuo $\mathrm{CL}$, Tsao $\mathrm{YH}$, Cheng HM, et al. Grommets for otitis media with effusion in children with cleft palate: a systematic review. Pediatrics 2014;134(5):983-994.

12. Kuo $C L$, Shiao AS, Yung $M$, et al. Updates and knowledge gaps in cholesteatoma research. Biomed Res Int 2015;2015:854024.

13. Kuo $\mathrm{CL}, \mathrm{CF}$, Shiao AS. Mastoid obliteration for pediatric suppurative cholesteatoma: long-term safety and sustained effectiveness after 30 years' experience with cartilage obliteration. Audiol Neurootol 2014;19(6):358-69.

14. Kuo CL. A critical appraisal of ventilation tube insertion in children with cleft palate. JAMA Otolaryngol Head Neck Surg 2015;141(2):189-190.

15. Kuo CL. Etiopathogenesis of acquired cholesteatoma: prominent theories and recent advances in biomolecular research. Laryngoscope 2015;125(1):234-240.

16. Sun $\mathrm{WH}$, Kuo CL, Huang TC. The anatomic applicability of transcanal endoscopic ear surgery in children. Int J Pediatr Otorhinolaryngol 2018;105:118-122.

17. Kuo $\mathrm{CL}$, Liao $\mathrm{WH}$, Shiao AS. A review of current progress in acquired cholesteatoma management. Eur Arch Otorhinolaryngol 2015;272(12):3601-3609.

18. Kuo CL, Shiao AS, Liao WH, Ho CY, Lien CF. How long is long enough 
to follow up children after cholesteatoma surgery? A 29-year study. Laryngoscope 2012;122(11):2568-2573.

19. Kuo CL. Chapter 12: Recent Advances in Understanding Pathogenesis of Acquired Cholesteatoma. Recent Advances in Otolaryngology Head and Neck Surgery, Vol. 5, P167-190. Anil K Lalwani, Markus HF Pfister. New Delhi, India: Jaypee Brothers Medical Publishers (P) Ltd, 2016.

20. Kuo CL, Shiao AS, Wen HC, Chang WP. Increased risk of cholesteatoma among patients with allergic rhinitis: a nationwide investigation. Laryngoscope 2018;128(3):547-553.

21. Kuo CL, Yen YC, Chang WP, Shiao AS. Association between middle ear cholesteatoma and chronic rhinosinusitis. JAMA Otolaryngol Head Neck Surg 2017;143(8):757-763.

22. Sharma RK, Nanda V. Problems of middle ear and hearing in cleft children. Indian J Plast Surg 2009;42 Suppl:S144-148.

23. Bluestone CD, Klein JO. Pediatric otolaryngology. In: 4th ed. Edited by Bluestone CD, Stool SE, Alper CM. Philadelphia: Saunders; 2003: 474-685.

24. Kuo CL, Wang MC, Chu CH, Shiao AS. New therapeutic strategy for treating otitis media with effusion in postirradiated nasopharyngeal carcinoma patients. J Chin Med Assoc 2012;75(7):329-334.

25. Chang CW, Yang YW, Fu CY, Shiao AS. Differences between children and adults with otitis media with effusion treated with $\mathrm{CO} 2$ laser myringotomy.J Chin Med Assoc 2012;75(1):29-35.

26. Takasaki K, Sando I, Balaban CD, Ishijima K. Postnatal development of eustachian tube cartilage. A study of normal and cleft palate cases. Int J Pediatr Otorhinolaryngol 2000;52(1):31-36.

27. Stool SE, Randall P. Unexpected ear disease in infants with cleft palate. Cleft PalateJ 1967;4:99-103.

28. Heidsieck DS, Smarius BJ, Oomen KP, Breugem CC. The role of the tensor veli palatini muscle in the development of cleft palate-associated middle ear problems. Clin Oral Investig 2016;20(7):1389-1401.

29. Bluestone CD. Studies in otitis media: Children's Hospital of Pittsburgh-University of Pittsburgh progress report-2004. Laryngoscope 2004;114(11 Pt 3 Suppl 105):1-26.

30. Rajion ZA, Al-Khatib AR, Netherway DJ, et al. The nasopharynx in infants with cleft lip and palate. Int J Pediatr Otorhinolaryngol 2012;76(2):227-234.

31. Kemaloglu YK, Kobayashi T, Nakajima T. Analysis of the craniofacial skeleton in cleft children with otitis media with effusion. Int J Pediatr Otorhinolaryngol 1999;47(1):57-69.

32. Rosenfeld RM, Goldsmith AJ, Tetlus L, Balzano A. Quality of life for children with otitis media. Arch Otolaryngol Head Neck Surg 1997;123(10):1049-1054

33. Sheahan P, Blayney AW, Sheahan JN, Earley MJ. Sequelae of otitis media with effusion among children with cleft lip and/or cleft palate. Clin Otolaryngol Allied Sci 2002;27(6):494-500.

34. Robinson PJ, Lodge S, Jones BM, Walker CC, Grant HR. The effect of palate repair on otitis media with effusion. Plast Reconstr Surg 1992;89(4):640-645.

35. Ruegg TA, Cooper ME, Leslie EJ, et al. Ear infection in isolated cleft lip: etiological implications. Cleft Palate Craniofac J 2017;54(2):189192.

36. Sheahan P, Miller I, Sheahan JN, Earley MJ, Blayney AW. Incidence and outcome of middle ear disease in cleft lip and/or cleft palate. Int J Pediatr Otorhinolaryngol 2003;67(7):785-793.

37. Chu KM, McPherson B. Audiological status of Chinese patients with cleft lip/palate. Cleft Palate Craniofac J 2005;42(3):280-285.

38. Phua YS, Salkeld LJ, de Chalain TM. Middle ear disease in children with cleft palate: protocols for management. Int J Pediatr Otorhinolaryngol 2009; 73(2):307-313.

39. Viswanathan $N$, Vidler $M$, Richard B. Hearing thresholds in newborns with a cleft palate assessed by auditory brain stem response. Cleft Palate Craniofac J 2008;45(2):187-192.
40. Bluestone CD, Beery QC, Cantekin El, Paradise JL. Eustachian tube ventilatory function in relation to cleft palate. Ann Otol Rhinol Laryngol 1975;84(3 Pt 1):333-338.

41. Goudy S, Lott D, Canady J, Smith RJ. Conductive hearing loss and otopathology in cleft palate patients. Otolaryngol Head Neck Surg 2006;134(6):946-948.

42. Harris L, Cushing SL, Hubbard B, Fisher D, Papsin BC, James AL. Impact of cleft palate type on the incidence of acquired cholesteatoma. Int J Pediatr Otorhinolaryngol 2013;77(5):695-698.

43. D'Mello J, Kumar S. Audiological findings in cleft palate patients attending speech camp. Indian J Med Res 2007;125(6):777-782.

44. Schonweiler R, Lisson JA, Schonweiler B, et al. A retrospective study of hearing, speech and language function in children with clefts following palatoplasty and veloplasty procedures at 18-24 months of age. Int J Pediatr Otorhinolaryngol 1999;50(3):205-217.

45. Rosenfeld RM, Culpepper L, Doyle KJ, et al. Clinical practice guideline: otitis media with effusion. Otolaryngol Head Neck Surg 2004;130(5 Suppl):S95-118.

46. Chen YW, Chen KT, Chang PH, Su JL, Huang CC, Lee TJ. Is otitis media with effusion almost always accompanying cleft palate in children? The experience of 319 Asian patients. Laryngoscope 2012;122(1):220-224.

47. Hall A, Wills AK, Mahmoud O, et al. Centre-level variation in outcomes and treatment for otitis media with effusion and hearing loss and the association of hearing loss with developmental outcomes at ages 5 and 7 years in children with non-syndromic unilateral cleft lip and palate: the Cleft Care UK study. Part 2. Orthod Craniofac Res 2017;20(Suppl 2):8-18.

48. Bess FH, Klee T, Culbertson JL. Identification, assessment, and management of children with unilateral sensorineural hearing loss. Ear Hear 1986;7(1):43-51.

49. Smith RM, McWilliams BJ. Creative thinking abilities of cleft palate children. Cleft Palate J 1966;3:275-283.

50. Paradise JL, Bluestone CD. Early treatment of the universal otitis media of infants with cleft palate. Pediatrics 1974;53(1):48-54.

51. Luthra S, Singh S, Nagarkar AN, Mahajan JK. The role of audiological diagnostics in children with cleft lip \& palate (CLP). Int J Pediatr Otorhinolaryngol 2009;73(10):1365-1367.

52. Guo YC, Shiao AS. Diagnostic methods for otitis media with effusion in children. Zhonghua Yi Xue Za Zhi (Taipei) 2002;65(8):372-377; discussion 363-374.

53. Wimmer E, Toleti B, Berghaus A, Baumann U, Nejedlo I. Impedance audiometry in infants with a cleft palate: the standard $226-\mathrm{Hz}$ probe tone has no predictive value for the middle ear condition. Int J Pediatr Otorhinolaryngol 2010;74(6):586-590.

54. Markey J, Maine R, Daniels K, et al. Otologic disease following palatoplasty in international cleft palate cohort. Cleft Palate Craniofac J 2018;55(2):162-167.

55. Halloran DR, Hardin JM, Wall TC. Validity of pure-tone hearing screening at well-child visits. Arch Pediatr Adolesc Med 2009;163(2):158-163.

56. Schwartz DM, Schwartz RH. Validity of acoustic reflectometry in detecting middle ear effusion. Pediatrics 1987;79(5):739-742.

57. Oyiborhoro JM, Olaniyan SO, Newman CW, Balakrishnan SL. Efficacy of acoustic otoscope in detecting middle ear effusion in children. Laryngoscope 1987;97(4):495-498.

58. Pellett FS, Cox LC, MacDonald CB. Use of acoustic reflectometry in the detection of middle ear effusion. J Am Acad Audiol 1997;8(3):181187.

59. Alt A. Heilunger Taubstummheit erzielte durch Bersitung einer otorrhooe einer angibornen Gaummenspalte. Arch Augenheilkd 1878;7:211-213.

60. Muntz HR. An overview of middle ear disease in cleft palate children. Facial Plast Surg 1993;9(3):177-180.

61. Flynn T, Lohmander A, Moller C, Magnusson L. A longitudinal study of hearing and middle ear status in adolescents with cleft lip and 
palate. Laryngoscope 2013;123(6):1374-1380.

62. Rynnel-Dagoo B, Lindberg K, Bagger-Sjoback D, Larson O. Middle ear disease in cleft palate children at three years of age. Int J Pediatr Otorhinolaryngol 1992;23(3):201-209.

63. Smith TL, DiRuggiero DC, Jones KR. Recovery of eustachian tube function and hearing outcome in patients with cleft palate. Otolaryngol Head Neck Surg 1994;111(4):423-429.

64. Robson AK, Blanshard JD, Jones K, Albery EH, Smith IM, Maw AR. A conservative approach to the management of otitis media with effusion in cleft palate children. J Laryngol Otol 1992;106(9):788-792.

65. NICE Clinical Guideline. Surgical management of otitis media with effusion in children. In., edn.: National Collaborating Centre for Women's and Children's Health (UK); 2008.

66. Gani B, Kinshuck AJ, Sharma R. A review of hearing loss in cleft palate patients. Int J Otolaryngol 2012;2012:548698.

67. Alper CM, Losee JE, Mandel EM, Seroky JT, Swarts JD, Doyle WJ. Preand post-palatoplasty Eustachian tube function in infants with cleft palate. Int J Pediatr Otorhinolaryngol 2012;76(3):388-391.

68. Andrews PJ, Chorbachi R, Sirimanna T, Sommerlad B, Hartley BE. Evaluation of hearing thresholds in 3-month-old children with a cleft palate: the basis for a selective policy for ventilation tube insertion at time of palate repair. Clin Otolaryngol Allied Sci 2004;29(1):10-17.

69. Ahn JH, Kang WS, Kim JH, Koh KS, Yoon TH. Clinical manifestation and risk factors of children with cleft palate receiving repeated ventilating tube insertions for treatment of recurrent otitis media with effusion. Acta Otolaryngol 2012;132(7):702-707.

70. Klockars T, Rautio J. Early placement of ventilation tubes in cleft lip and palate patients: does palatal closure affect tube occlusion and short-term outcome? Int J Pediatr Otorhinolaryngo/ 2012;76(10):14811484.

71. Valtonen H, Dietz A, Qvarnberg Y. Long-term clinical, audiologic, and radiologic outcomes in palate cleft children treated with early tympanostomy for otitis media with effusion: a controlled prospective study. Laryngoscope 2005;115(8):1512-1516.

72. Ovesen T, Blegvad-Andersen O. Alterations in tympanic membrane appearance and middle ear function in 11-year-old children with complete unilateral cleft lip and palate compared with healthy agematched subjects. Clin Otolaryngol Allied Sci 1992;17(3):203-207.

73. He Y, Xu H, Zhen Q, Liao X, Xu L, Zhen Y. The influence of palatoplasty and tympanotomy on middle ear function in cleft palate patients. Hua Xi Kou Qiang Yi Xue Za Zhi 2001;19(4):243-245.

74. Koempel JA, Kumar A. Long-term otologic status of older cleft palate patients. Indian J Pediatr 1997;64(6):793-800.

75. Fria TJ, Paradise JL, Sabo DL, Elster BA. Conductive hearing loss in infants and young children with cleft palate. J Pediatr 1987;111(1):8487.

76. Frable MA, Brandon GT, Theogaraj SD. Velar closure and ear tubings as a primary procedure in the repair of cleft palates. Laryngoscope 1985;95(9 Pt 1):1044-1046.

77. Moller P. Hearing, middle ear pressure and otopathology in a cleft palate population. Acta Otolaryngol 1981;92(5-6):521-528.

78. Zheng $\mathrm{Q}, \mathrm{Xu} \mathrm{H}, \mathrm{He} Y$. Effects of tympanotomy and pressure equilibrium tube insertion during palatoplasty on prognoses of otitis media with effusion. Hua Xi Kou Qiang Yi Xue Za Zhi 2003;21(1):28-30.

79. Broen PA, Moller KT, Carlstrom J, Doyle SS, Devers M, Keenan KM. Comparison of the hearing histories of children with and without cleft palate. Cleft Palate Craniofac J 1996;33(2):127-133.

80. Hubbard TW, Paradise JL, McWilliams BJ, Elster BA, Taylor FH. Consequences of unremitting middle-ear disease in early life. Otologic, audiologic, and developmental findings in children with cleft palate. N EnglJ Med 1985;312(24):1529-1534.

81. Kwan WM, Abdullah VJ, Liu K, van Hasselt CA, Tong MC. Otitis media with effusion and hearing loss in Chinese children with cleft lip and palate. Cleft Palate Craniofac J 2011;48(6):684-689.
82. Hornigold R, Morley A, Glore RJ, Boorman J, Sergeant R. The longterm effect of unilateral t-tube insertion in patients undergoing cleft palate repair: 20-year follow-up of a randomised controlled trial. Clin Otolaryngol 2008;33(3):265-268.

83. Chen JL, Messner AH, Curtin G. Newborn hearing screening in infants with cleft palates. Otol Neurotol 2008;29(6):812-815.

84. Li W, Shang W, Yu AH, et al. Early treatment of middle ear disease in cleft palate infants. Hua Xi Kou Qiang Yi Xue Za Zhi 2007;25(5):458462.

85. Liu L, Sun YG, Ma L, Zhao W, Wu R. Effect of ventilation tube insertion on otitis media with effusion in cleft palate children. Zhonghua Er Bi Yan Hou Ke Za Zhi 2004;39(4):216-218.

86. Maheshwar AA, Milling MA, Kumar M, Clayton MI, Thomas A. Use of hearing aids in the management of children with cleft palate. Int J Pediatr Otorhinolaryngol 2002;66(1):55-62.

87. Gordon AS, Jean-Louis F, Morton RP. Late ear sequelae in cleft palate patients. Int J Pediatr Otorhinolaryngol 1988;15(2):149-156.

88. Potsic WP, Cohen M, Randall P, Winchester R. A retrospective study of hearing impairment in three groups of cleft palate patients. Cleft Palate J 1979;16(1):56-58.

89. Merrick GD, Kunjur J, Watts R, Markus AF. The effect of early insertion of grommets on the development of speech in children with cleft palates. Br J Oral Maxillofac Surg 2007;45(7):527-533.

90. Kobayashi H, Sakuma T, Yamada N, Suzaki H. Clinical outcomes of ventilation tube placement in children with cleft palate. Int J Pediatr Otorhinolaryngol 2012;76(5):718-721.

91. Shaw R, Richardson D, McMahon S. Conservative management of otitis media in cleft palate. J Craniomaxillofac Surg 2003;31(5):316320.

92. Freeland AP, Evans DM. Middle ear disease in the cleft palate infant: its effect on speech and language development. Br J Plast Surg 1981;34(2):142-143.

93. Spilsbury K, Ha JF, Semmens JB, Lannigan F. Cholesteatoma in cleft lip and palate: a population-based follow-up study of children after ventilation tubes. Laryngoscope 2013;123(8):2024-2029.

94. Kay DJ, Nelson M, Rosenfeld RM. Meta-analysis of tympanostomy tube sequelae. Otolaryngol Head Neck Surg 2001;124(4):374-380.

95. Golz A, Goldenberg D, Netzer A, et al. Cholesteatomas associated with ventilation tube insertion. Arch Otolaryngol Head Neck Surg 1999;125(7):754-757.

96. Herdman R, Wright JL. Grommets and cholesteatoma in children. $J$ Laryngol Otol 1988;102(11):1000-1002.

97. Hellstrom S, Groth A, Jorgensen F, et al. Ventilation tube treatment: a systematic review of the literature. Otolaryngol Head Neck Surg 2011;145(3):383-395.

98. Moller P. Selective use of ventilating tubes in the treatment of secretory otitis media and retractions of the eardrum. Acta Otolaryngol 1982;94(suppl 386):158-160.

99. Curtin G, Messner AH, Chang KW. Otorrhea in infants with tympanostomy tubes before and after surgical repair of a cleft palate. Arch Otolaryngol Head Neck Surg 2009;135(8):748-751.

100. Tengroth B, Hederstierna C, Neovius E, Flynn T. Hearing thresholds and ventilation tube treatment in children with unilateral cleft lip and palate. Int J Pediatr Otorhinolaryngol 2017;97:102-108.

101. Shapiro RS. Otologic findings in an Inuit population of cleft palate children. J Otolaryngol 1988;17(2):101-102.

102. Yamamoto Y, Takahashi K, Morita Y, Takahashi S. Clinical behavior and pathogenesis of secondary acquired cholesteatoma with a tympanic membrane perforation. Acta Otolaryngol 2013;133(10):1035-1039.

103. Kuo CL. In reference to a new theory on the pathogenesis of acquired cholesteatoma: mucosal traction. Laryngoscope 2016;126(3):E132.

104. Vlastarakos PV, Nikolopoulos TP, Korres S, Tavoulari E, Tzagaroulakis A, Ferekidis E. Grommets in otitis media with effusion: the most frequent operation in children. But is it associated with significant 
complications? Eur J Pediatr 2007;166(5):385-391.

105. Caglar O, Bulbul F, Sennaroglu L. Incidence of otitis media with effusion and long-term clinical findings in children with cleft lip and palate types. Kulak Burun Bogaz Ihtis Derg 2013;23(5):268-274.

106. Kuscu O, Gunaydin RO, Icen M, et al. The effect of early routine grommet insertion on management of otitis media with effusion in children with cleft palate. J Craniomaxillofac Surg 2015;43(10):21122115.

107. Lithovius RH, Lehtonen $\mathrm{V}$, Autio TJ, et al. The association of cleft severity and cleft palate repair technique on hearing outcomes in children in northern Finland. J Craniomaxillofac Surg 2015;43(9):1863-1867.

108. Huang CY, Wu CS, Tang CH, Wang MC, Kuo TY, Tu TY. Palatoplasty decreases the re-insertion rate of middle ear ventilation tube in cleft palate children - A population-based birth cohort study. Acta Otolaryngol 2016;136(8):768-774.

109. Daniel M, Kamani T, El-Shunnar S, et al. National Institute for Clinical Excellence guidelines on the surgical management of otitis media with effusion: are they being followed and have they changed practice? Int J Pediatr Otorhinolaryngol 2013;77(1):54-58.

110. Rosenfeld RM, Shin J, Schwartz SR, et al. Clinical practice guideline: otitis media with effusion Executive summary (update). Otolaryngol Head Neck Surg 2016;154(2):201-214.

111. Browning GG, Rovers MM, Williamson I, Lous J, Burton MJ. Grommets (ventilation tubes) for hearing loss associated with otitis media with effusion in children. Cochrane Database Syst Rev 2010;(10):CD001801.

112. Sheahan $P$, Blayney AW. Cleft palate and otitis media with effusion: a review. Rev Laryngol Otol Rhinol (Bord) 2003;124(3):171-177.

113. Paradise JL. Middle ear problems associated with cleft palate. An internationally-oriented review. Cleft Palate J 1975;12(00):17-22.

114. Yules RB. Current concepts of treatment of ear disease in cleft palate children and adults. Cleft Palate J 1975;12:315-322.

115. Rosenfeld RM, Schwartz SR, Pynnonen MA, et al. Clinical practice guideline: tympanostomy tubes in children. Otolaryngol Head Neck
Surg 2013;149(1 Suppl):S1-35.

116. Wallace IF, Berkman ND, Lohr KN, Harrison MF, Kimple AJ, Steiner MJ. Surgical treatments for otitis media with effusion: a systematic review. Pediatrics 2014;133(2):296-311.

117. Berkman ND, Wallace IF, Steiner MJ, et al. Otitis media with effusion: comparative effectiveness of treatments. Comparative Effectiveness Review No 101 (Prepared by the RTI-UNC Evidence-based Practice Center under Contract No 290-2007-10056-1) 2013.

118. McDonald S, Langton Hewer CD, Nunez DA. Grommets (ventilation tubes) for recurrent acute otitis media in children. Cochrane Database Syst Rev 2008;(4):CD004741.

119. Perera R, Haynes J, Glasziou P, Heneghan CJ. Autoinflation for hearing loss associated with otitis media with effusion. Cochrane Database Syst Rev 2006;(4):CD006285.

120. van den Aardweg MT, Schilder AG, Herkert E, Boonacker CW, Rovers MM. Adenoidectomy for otitis media in children. Cochrane Database Syst Rev 2010;(1):CD007810.

121. van Zon A, van der Heijden GJ, van Dongen TM, Burton MJ, Schilder AG. Antibiotics for otitis media with effusion in children. Cochrane Database Syst Rev 2012;(9):CD009163.

122. Higgins JPT, Green S (editors). Cochrane Handbook for Systematic Reviews of Interventions [Version 5.1.0]. March 2011. The Cochrane Collaboration. Available at: http://handbook.cochrane.org. 2011.

123. Liberati A, Altman DG, Tetzlaff J, et al. The PRISMA statement for reporting systematic reviews and meta-analyses of studies that evaluate health care interventions: explanation and elaboration. PLOS Med 2009;6(7):e1000100.

124. Moher D, Shamseer L, Clarke M, et al. Preferred reporting items for systematic review and meta-analysis protocols (PRISMA-P) 2015 statement. Syst Rev 2015;4:1.

125. Smallridge J, Hall AJ, Chorbachi R, et al. Functional outcomes in the Cleft Care UK study. Part 3: oral health and audiology. Orthod Craniofac Res 2015;18(Suppl 2):25-35. 